\title{
Influence of Strain Aging on the Ductility of 05Г2ФБ Steel in Controlled Rolling and Accelerated Cooling
}

\author{
A. B. Arabei ${ }^{a}$, V. M. Farber ${ }^{b}$, I. Yu. Pyshmintsev ${ }^{c}$, V. A. Khotinov ${ }^{b}$, O. V. Selivanova ${ }^{b}$, \\ N. V. Lezhnin ${ }^{b}$, and M. A. Valov \\ ${ }^{a} \mathrm{OAO}$ Gazprom \\ ${ }^{b}$ Ural Federal University \\ ${ }^{c}$ Russian Research Institute of the Pipe Industry \\ Received July 30, 2012
}

DOI: $10.3103 / \mathrm{S} 0967091212110022$

Today's pipe steels have a distinctive set of mechanical properties, primarily thanks to the ultrasmall grains $(\sim 2-3 \mu \mathrm{m})$ obtained by controlled rolling and accelerated cooling [1, 2]. However, it is assumed that these properties deteriorate on strain aging in the steel-when carbon and nitrogen atoms leave the lattice of ferrite and bainite (martensite) supersaturated with these elements as a result of accelerated cooling. The loss of $\mathrm{C}$ and $\mathrm{N}$ atoms from the solid solution leads to the formation of segregations (Cottrell atmospheres) at dislocations and grain boundaries. Those segregations are subsequently converted to disperse deposits of type $\mathrm{Me}_{3}(\mathrm{C}, \mathrm{N})[3,4]$. On the $\sigma-\varepsilon$ diagrams for the extension of industrial-grade iron and low-carbon steel, a fluidity bump (upper yield point $\sigma_{\mathrm{y}}^{\mathrm{U}}$ ) appears and gives way to a fluidity region when the metal flows at constant stress $\sigma_{\mathrm{y}}^{\mathrm{L}}$ (the lower yield point). These effects are much more pronounced in polycrystals than in single crystals $[4,5]$. This difference may probably be explained by the pronounced contribution of the grain boundaries (grain-boundary dislocations) to the formation of the fluidity region [6]. The influence of the grain boundaries is seen in that the fluidity region is more evident for samples cut from the sheet transverse to the rolling direction [3].

Analysis of the experimental data indicates that the fluidity region is associated with the following factors $[3,6]$.

(1) The metal lacks mobile plastic-flow carriers, such as lattice and grain-boundary dislocations and free vacancies, because they are pinned by impurity-atom atmospheres and disperse secondary-phase particles.

(2) The dislocations move easily once they break away from the impurity atmospheres and disperse particles. That is typical, in particular, of low-carbon iron (ferrite).

Strain aging impairs the plasticity of industrialgrade iron and low-carbon ferrite-pearlite and ferrite-bainite steel $[3,4]$. That calls for special tests on the susceptibility of steel to strain aging, in accordance with GOST (State Standard) 7268-82 [7].

In addition, strain aging is facilitated by ultrasmall grains and the increased dislocation density in metals after the processes used in welded-pipe manufacture (shaping, expansion, etc. [8]) and the application of insulating coatings [9]. A similar situation is observed in the thermal-influence zone of weld joints and also in the course of natural aging with prolonged pipe storage and/or operation (more than a year and a half).

In the present work, on that basis, we study the influence of low-temperature aging on the extension and impact-flexure diagrams and also the mechanical prop-

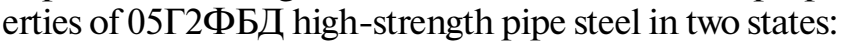

(1) in its initial condition, after controlled rolling and accelerated cooling;

(2) after slight plastic deformation.

\section{EXPERIMENTAL METHOD}

We study samples cut from welded pipe of strength category K65 (X80) supplied by two producers (steel 1 and steel 2). The chemical composition of the steel (wt \%) is as follows:

$$
\begin{array}{cccccc}
\text { Steel } & \mathrm{C} & \mathrm{Mn} & \Sigma(\mathrm{V}+\mathrm{Nb}+\mathrm{Ti}) \Sigma(\mathrm{V}+\mathrm{Nb}+\mathrm{Ni}) & \mathrm{Cu} \\
1 & 0.05 & 1.84 & 0.12 & - & 0.06 \\
2 & 0.07 & 1.67 & - & 0.08 & 0.18
\end{array}
$$

Extension and impact-flexure tests are conducted on samples in the initial state and after the following treatment: in air;

—aging for $30 \mathrm{~min}$ at $100,150,250^{\circ} \mathrm{C}$ with cooling

- preliminary $2 \%$ deformation and subsequent aging for $30 \mathrm{~min}$ at $200^{\circ} \mathrm{C}$ with cooling in air;

-aging for $30 \mathrm{~min}$ at $150^{\circ} \mathrm{C}$ with subsequent deformation $(\varepsilon=2 \%)$ and repeated aging for $30 \mathrm{~min}$ at $200^{\circ} \mathrm{C}$. 


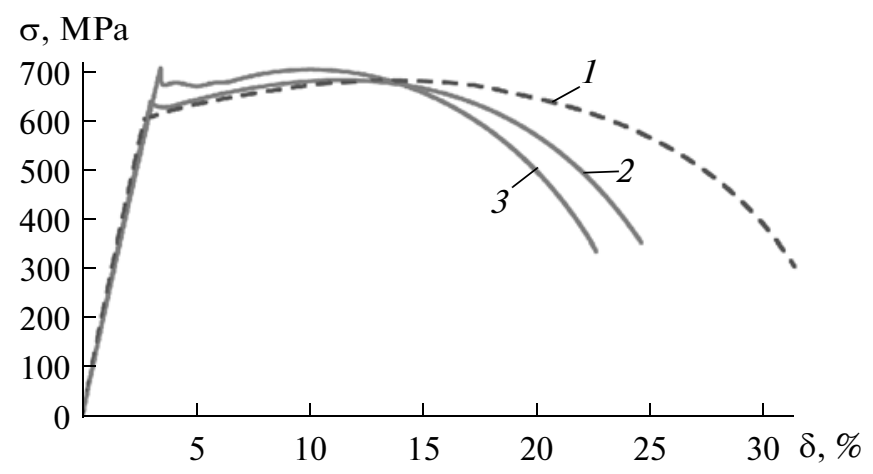

Fig. 1. Extension of steel 1 samples from the initial pipe (1) and after aging at $150^{\circ} \mathrm{C} \mathrm{(2)} \mathrm{and} 250^{\circ} \mathrm{C} \mathrm{(3)}$.

The mechanical properties of the steel are studied in tensile tests at room temperature and in impactflexure tests on Charpy samples in the range from 20 to $-80^{\circ} \mathrm{C}$, with oscillographic recording of the load $P$ and energy $K C$ as a function of the flexure $l$ in an Instron CEAST 9350 machine.

\section{RESULTS AND DISCUSSION}

\section{Tensile Tests}

On the extension diagram of samples cut from the pipe after brief storage, we see no fluidity bump or fluidity region (Fig. 1). That indicates a considerable quantity of free plastic-flow carriers (lattice and grainboundary dislocations) that are not pinned by segregations of dissolved atoms and disperse particles. The strength of the initial pipe from both producers is practically the same (Fig. 2). At the stage of uniform deformation, the curve is parabolic.

Aging at $T_{\mathrm{t}}=100^{\circ} \mathrm{C}$ reduces the yield point $\sigma_{0.2}$ and strength $\sigma_{\mathrm{B}}$ of steel 1 by $\sim 40 \mathrm{MPa}$ and also reduces the fracture stress $S_{\text {cr }}$ and plasticity. For steel 2, by contrast, the strength and plasticity remain unchanged. No fluidity bump or fluidity region is seen on the tensile diagrams of steels 1 and 2 . That indicates the absence of any pronounced strain aging.

On the extension diagram of steel 1 aged at $T_{\mathrm{t}}=$ $150^{\circ} \mathrm{C}$, we clearly see a fluidity bump and fluidity region (Fig. 1). The effect is less pronounced for steel 2, although the extent of the fluidity region $\delta_{\mathrm{f}}$ is the same in both cases (Fig. 3). The fluidity region is followed by a stage of parabolic flow, whose extent $(\sim 8.4 \%)$ is scarcely less than for samples in the initial state. For steels 1 and 2, $\sigma_{\mathrm{y}}^{\mathrm{L}}$ increases markedly (by $20 \mathrm{MPa}$ ), without change in $\sigma_{\mathrm{B}}$ (Fig. 2). For steels 1 and 2, $S_{\mathrm{cr}}$ increases by 30 and $70 \mathrm{MPa}$, respectively. The relative uniform elongation $\delta_{\mathrm{u}}$ and the relative elongation in point deformation $\delta_{\mathrm{p}}$ decline for steel 1 , but remain almost unchanged for steel 2 (Fig. 3). All in all, this
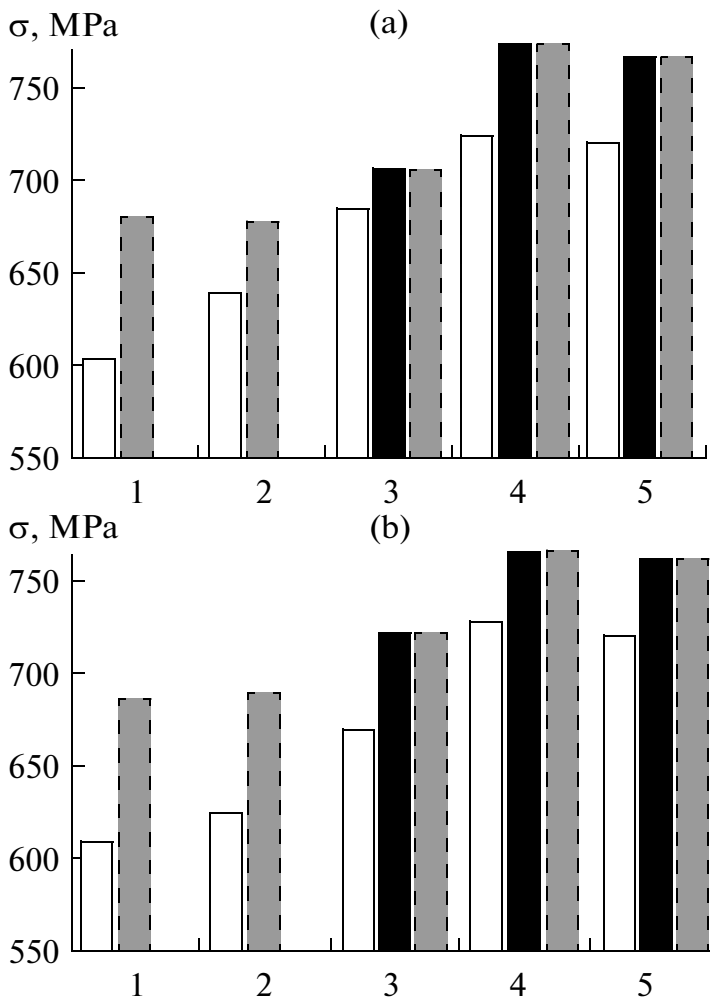

Fig. 2. Strength of steel 1 (a) and steel 2 (b): (1) initial pipe; (2) after aging at $150^{\circ} \mathrm{C}$; (3) after aging at $250^{\circ} \mathrm{C}$; (4) after deformation $(\varepsilon=2 \%)+$ aging at $200^{\circ} \mathrm{C} ;(5)$ after aging at $150^{\circ} \mathrm{C}+$ deformation $(\varepsilon=2 \%)+$ aging at $200^{\circ} \mathrm{C} ;(\square)$ lower yield point $\sigma_{\mathrm{y}}^{\mathrm{L}} ;(\boldsymbol{\square})$ upper yield point $\sigma_{\mathrm{y}}^{\mathrm{U}} ;(\square) \sigma_{\mathrm{B}}$.

indicates that strain aging at $T_{\mathrm{t}}=150^{\circ} \mathrm{C}$ is somewhat more vigorous in steel 1 than in steel 2 .

The variation in the mechanical properties observed on aging at $150^{\circ} \mathrm{C}$ is intensified at $T_{\mathrm{t}}=$ $250^{\circ} \mathrm{C}$, for both steels (Figs. 1-3). The fluidity bump (the upper yield point $\sigma_{y}^{U}$ ) is higher. In addition, on account of the fast increase in $\sigma_{\mathrm{y}}^{\mathrm{L}}$, it approaches $\sigma_{\mathrm{B}}$ $\left(\sigma_{\mathrm{y}}^{\mathrm{L}} / \sigma_{\mathrm{B}} \approx 0.96\right)$, and consequently the uniform elongation $\delta_{\mathrm{u}}$ is reduced. The decrease in plasticity $\left(\delta_{\mathrm{u}}, \delta_{\mathrm{p}}\right)$ with increase in the fluidity region $\left(\delta_{\mathrm{f}}\right)$ is especially pronounced for steel 2 (Fig. 3).

In pipe transportation and installation and pipeline operation, the metal may undergo local plastic deformation, which should intensify the strain aging. To simulate this effect, samples cut from the initial pipe and pipe aged at $T_{\mathrm{t}}=150^{\circ} \mathrm{C}$ are deformed by $2 \%$ with subsequent aging at $200^{\circ} \mathrm{C}$.

Such treatment sharply increases the strain aging, regardless of the sequence of operations (Figs. 2 and 3 ). In both steels, the yield point increases much more than $\sigma_{\mathrm{B}}$. On the extension diagram, the stage of parabolic strengthening disappears. Such an anomalous 

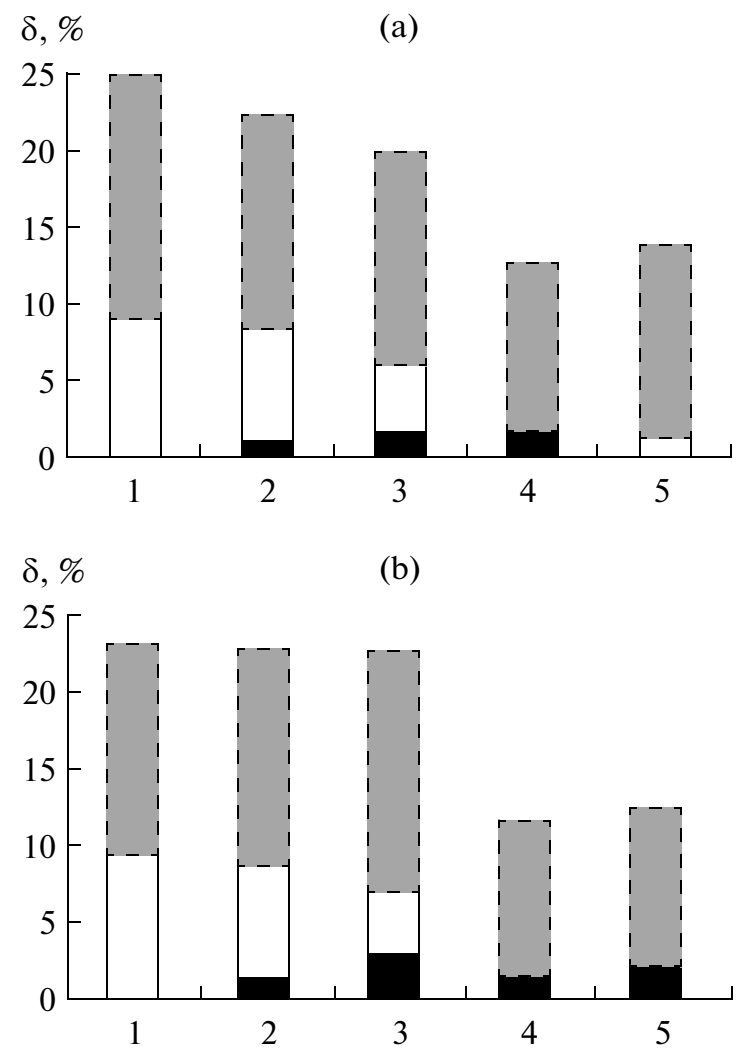

Fig. 3. Plasticity of steel 1 (a) and steel 2 (b): (1) initial pipe; (2) after aging at $150^{\circ} \mathrm{C} ; 3$ ) after aging at $250^{\circ} \mathrm{C}$; (4) after deformation $(\varepsilon=2 \%)+$ aging at $200^{\circ} \mathrm{C} ;(5)$ after aging at $150^{\circ} \mathrm{C}+$ deformation $(\varepsilon=2 \%)+$ aging at $200^{\circ} \mathrm{C}$; $(\square) \delta_{\mathrm{u}} ;(\boldsymbol{\square})$ extent of fluidity region $\left(\delta_{\mathrm{f}}\right) ;(\square) \delta_{\mathrm{p}}$.

extension diagram, together with the appearance of a depression on the extension diagram immediately after the Luders front passes through the working part of the sample, may be observed for steel $(0.06 \% \mathrm{C}$, $0.5 \% \mathrm{Mn}$, and $0.1 \% \mathrm{Nb}$ ) with supersmall ferrite grains $(1.7 \mu \mathrm{m})$ obtained by high-temperature thermomechanical treatment $\left(T_{\text {def }}=900^{\circ} \mathrm{C}\right)$ and subsequent air cooling [10]. That again indicates the significant contribution of the grain boundary (grain-boundary dislocations) to strain aging.

In the absence of uniform deformation, the total elongation $\delta_{5}$ for both steels is reduced by almost half (Fig. 3), although $S_{\mathrm{cr}} \approx 1600 \mathrm{MPa}$ and the relative constriction $\psi \approx 78 \%$ remain relatively high.

To assess the strain aging in the absence of defects introduced by sheet and pipe production (extended grain boundaries in austenite, increased dislocation density), samples cut from the pipe are quenched in oil after austenitization at $T_{\mathrm{a}}=900^{\circ} \mathrm{C}$. In particular, that structural state may appear in the thermal-influence zone of weld joints.

Quenching reduces $\sigma_{0.2}$ by $40 \mathrm{MPa}$ for steel 1 and $9 \mathrm{MPa}$ for steel 2. In both steels, $\sigma_{\mathrm{B}}$ is increased by $65 \mathrm{MPa}$, possibly on account of increased bainite and
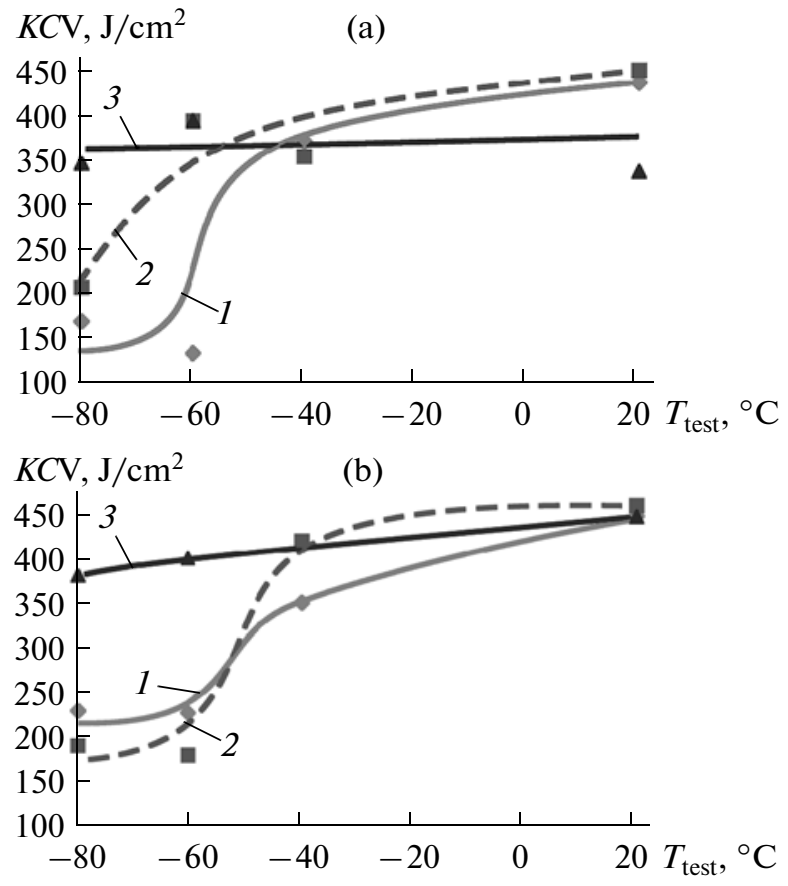

Fig. 4. Serial curves of the impact strength: (a) steel 1; (b) steel 2; (1) initial pipe; (2) $T_{\mathrm{t}}=150^{\circ} \mathrm{C}$; (3) $T_{\mathrm{t}}=250^{\circ} \mathrm{C}$.

martensite content. These trends are retained on aging quenched samples at $150^{\circ} \mathrm{C}$. The extension curves are smooth, without a fluidity bump or fluidity region, and the uniform elongation is relatively small $\left(\delta_{\mathrm{u}} \sim 5 \%\right)$.

Quenching markedly reduces $\delta_{\mathrm{p}}$ (Fig. 3); that is accompanied by decrease in $\delta_{5}$ from $\sim 23-25 \%$ to $\sim 17 \%$. There is no change in $\psi$ or $S_{\mathrm{cr}}$.

\section{Impact-Flexure Tests}

In the initial state, steels 1 and 2 are characterized by high impact strength $\left(K C \mathrm{~V}>350 \mathrm{~J} / \mathrm{cm}^{2}\right)$ down to $T_{\text {test }}=-40^{\circ} \mathrm{C}$. In samples cut from pipe, $K C \mathrm{~V}$ declines sharply at temperatures between -40 and $-60^{\circ} \mathrm{C}$, for both steels.

Aging at $150^{\circ} \mathrm{C}$ has no significant influence on the impact strength, but the temperature at which $K C \mathrm{~V}$ begins to decline falls to around $-60^{\circ} \mathrm{C}$ in steel 1 . Aging at $250^{\circ} \mathrm{C}$ results in some drop in $K C V$ at $T_{\text {test }}=$ $20^{\circ} \mathrm{C}$, but both steels are insensitive to test temperatures down to $T_{\text {test }}=-80^{\circ} \mathrm{C}$. This is especially clear below $-40^{\circ} \mathrm{C}$, where the difference in $K C \mathrm{~V}$ for the initial samples and samples aged at $250^{\circ} \mathrm{C}$ is $150-$ $200 \mathrm{~J} / \mathrm{cm}^{2}$ (Fig. 4).

If samples cut from pipe are quenched from $900^{\circ} \mathrm{C}$ in oil, the impact strength is about the same as for pipe samples at all test temperatures. No cleavage is seen in the fracture, because the heating prior to quenching leads to phase recrystallization and the disappearance of the large-angle boundaries at which cleavage begins. 

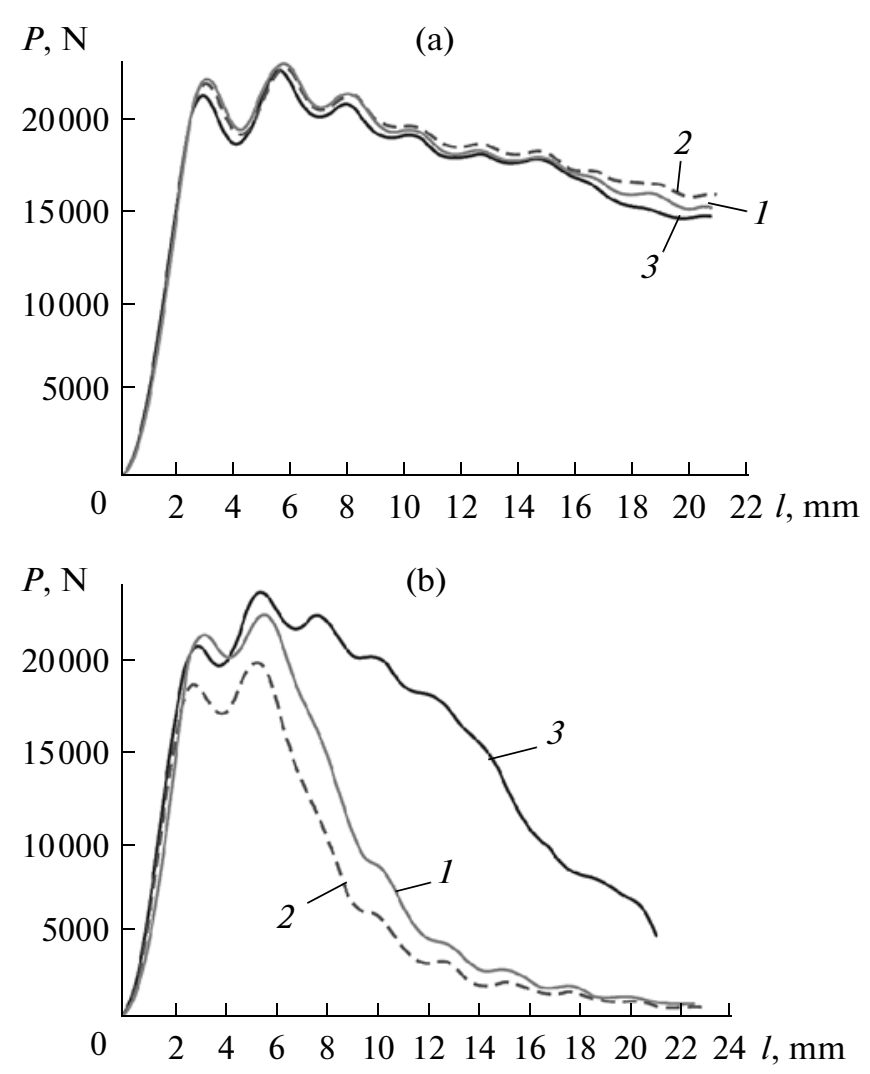

Fig. 5. Fracture diagrams of steel 2 Charpy samples in terms of the load $P$ and flexure $l$ : (a) $T_{\text {test }}=20^{\circ} \mathrm{C}$; (b) $T_{\text {test }}=-60^{\circ} \mathrm{C}$; (1) initial pipe; (2) $T_{\mathrm{t}}=150^{\circ} \mathrm{C} ; T_{\mathrm{t}}=250^{\circ} \mathrm{C}$.

Investigation of the crack resistance by means of fracture diagrams permits detailed analysis of the influence of strain aging on the impact strength. As is evident from Fig. 5a, strain aging has practically no influence on the strength of steel 2 (and analogously steel 1) at room temperature.

The agreement of the load peaks on the $P-l$ diagrams in the initial stage of loading (from the appearance of the crack to the first maximum $[11,12]$ ) indicates that, at $T_{\text {test }}=20^{\circ} \mathrm{C}$, the difference in the structural state does not much change the work of crack initiation $\left(K C_{\text {in }}\right)$, which is $\sim 87 \mathrm{~J}$ for both steels. At room temperature, $K C_{\text {in }}$ is about a third of the work of crack propagation $\left(K C_{\mathrm{pr}}\right)$. However, with decrease in test temperature to $-60^{\circ} \mathrm{C}$, these values are comparable.

Since $K C_{\text {in }} \approx$ const in all the cases considered, the variation in $K C \mathrm{~V}$ (Fig. 4) is basically due to the change in $K C_{\mathrm{pr}}$, which varies analogously to the impact strength $K C V$ with variation in $T_{\text {test }}$.

Aging at $150^{\circ} \mathrm{C}$ has little effect on $K C V$ and the shape of the curve or on the sequence of failure stages at all $T_{\text {test }}$ (Fig. 4).

The large area under the $P-l$ curve for samples aged at $250^{\circ} \mathrm{C}$ is associated with smoother reduction in load in the final stages of failure (Fig. 5). The work of plastic deformation and crack propagation $(K C)$ for those

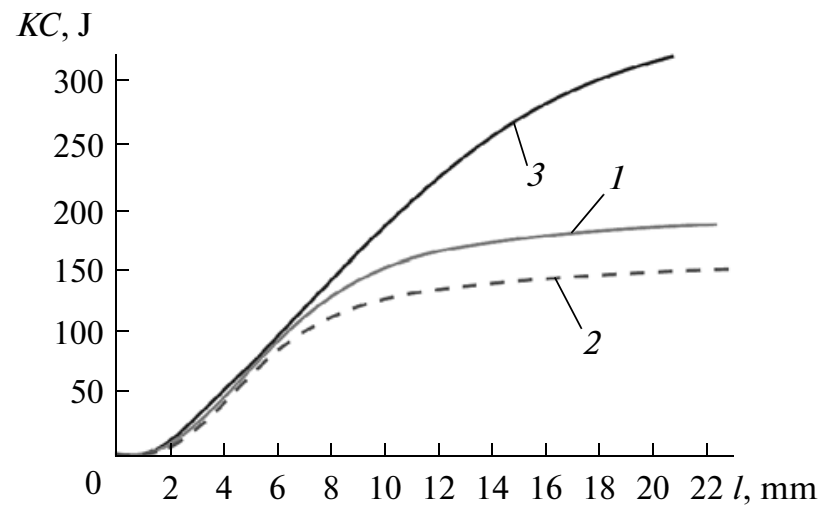

Fig. 6. Fracture diagrams of steel 2 Charpy samples in terms of the energy $K C$ and flexure $l$ at $T_{\text {test }}=-60^{\circ} \mathrm{C}$ : (1) initial pipe; (2) $T_{\mathrm{t}}=150^{\circ} \mathrm{C} ; T_{\mathrm{t}}=250^{\circ} \mathrm{C}$.

samples is also significant greater than for samples cut from pipe (Fig. 6). That indicates greater mobility (maneuverability) of dislocations as a result of heating. The same pattern is observed at $T_{\text {test }}=-40^{\circ} \mathrm{C}$. In that case, the serial curve in Fig. 4 becomes less steep, with shift in the ductile-brittle transition temperature $T_{\mathrm{br}}$ below $-80^{\circ} \mathrm{C}$.

Thus, aging at $250^{\circ} \mathrm{C}$ sharply increases the crack resistance of X80 steel, on account of the following factors:

- loss of $\mathrm{C}$ and $\mathrm{N}$ atoms from the solid solution;

- enlargement of the deposits of $\mathrm{Fe}$ and $\mathrm{Cu}$ carbonitrides;

- liberation and organization of the dislocations in stable configurations, with the consequent removal of residual stress.

This agrees with tensile data for the same steels: in aged samples, the $S_{\mathrm{cr}}$ and $\psi$ values describing the final stage in plastic flow prior to failure are the same as for samples cut from pipe. Hence, at the beginning of plastic flow $\left(\right.$ at $\sigma_{\mathrm{y}}$ ), strain aging has no significant influence on the crack resistance of heterophase steels in which failure occurs after extremely large plastic deformation. Thus, in such steels, the impact strength correlates with $S_{\mathrm{cr}}$ and $\psi$ and does not depend on $\sigma_{\mathrm{y}}$ $\left(S_{\mathrm{y}}\right)$ or $\sigma_{\mathrm{B}}\left(S_{\mathrm{B}}\right)$, as shown in [13].

Finally, low-temperature heating $\left(T_{\mathrm{t}} \leq 250^{\circ} \mathrm{C}\right)$ of heterophase steels leads to true strain aging in ferrite and to softening low-temperature tempering of bainite (martensite), which constitutes up to $30 \%$ of the steel $[1,2]$. Thus, the softening of such steel improves their ductility and crack resistance, as already noted.

\section{CONCLUSIONS}

Pipe steel of strength category X80 produced by controlled rolling and accelerated cooling or by mild quenching (in oil) is susceptible to strain aging at $T_{\mathrm{t}} \geq$ $150^{\circ} \mathrm{C}$. Strain aging results in the appearance of a flu- 
idity bump and fluidity region on the extension diagrams, increase in the lower yield point $\sigma_{\mathrm{y}}^{\mathrm{L}}$, decrease in $\delta_{\mathrm{u}}$ and $\delta$, and no change in $\sigma_{\mathrm{B}}, \psi$, and the fracture stress $S_{\text {cr. }}$.

The strain aging produced by heating at $T_{\mathrm{t}}=250^{\circ} \mathrm{C}$ $\left(\tau_{\mathrm{t}}=30 \mathrm{~min}\right)$ and, in particular, by cold plastic deformation $(\varepsilon=2 \%)$ with subsequent heating at $200^{\circ} \mathrm{C}$ $\left(\tau_{\mathrm{t}}=30 \mathrm{~min}\right)$ is so strong that $\sigma_{\mathrm{y}}^{\mathrm{L}} \approx \sigma_{\mathrm{B}}$ and $\delta_{\mathrm{u}}=0 \%$, with decrease in the total elongation $\delta$. There is little change in $\psi$ and $S_{\text {cr }}$, which describe the large plastic deformation preceding failure. Hence, strain aging is greatly promoted by the processes employed in welded-pipe production (fracture, expansion, etc.), which increase the defect density.

After heating at $T_{\mathrm{t}} \leq 150^{\circ} \mathrm{C}$, the characteristics of crack resistance ( $K C \mathrm{~V}$, the form of the serial curve, $\left.T_{\mathrm{br}}\right)$ remain unchanged. Heating at $T_{\mathrm{t}}=250^{\circ} \mathrm{C}\left(\tau_{\mathrm{t}}=\right.$ $30 \mathrm{~min}$ ) somewhat reduces $K C \mathrm{~V}$ (to $\sim 370 \mathrm{~J} / \mathrm{cm}^{2}$ at $T_{\text {test }}<$ $-40^{\circ} \mathrm{C}$ ) and makes the serial curve practically insensitive to $T_{\text {test }}$ between -20 and $-80^{\circ} \mathrm{C}$, since $T_{\text {br }}$ is shifted below $-80^{\circ} \mathrm{C}$.

\section{REFERENCES}

1. Morozov, Yu.D., Matrosov, M.Yu., Nastich, S.Yu., and Arabei, A.B., Metallurg, 2008, no. 8, pp. 39-42.

2. Pyshmintsev, I.Yu., Stolyarov, V.I., Gervas'ev, A.M., et al., Nauka Tekh. Gaz. Prom., 2009, no. 1, pp. 56-61.

3. Houdremont, E., Handbook of Special Steels, Berlin: Springer, 1956.
4. Friedel, J., Dislocations, Reading, Mass.: Addison Wesley, 1964.

5. Shtremel', M.A., Prochnost' splavov: Ch. 1. Defekty reshetki (Alloy Strength, Vol. 1: Lattice Defects), Moscow: MISIS, 1999.

6. Farber, V.M., Metallov. Term. Obrab. Met., 2007, no. 3, pp. 42-44.

7. GOST (State Standard) 7268-82: Steel: Method of Determining the Susceptibility to Mechanical Aging in Impact-Flexure Tests, 2002.

8. Pyshmintsev, I.Yu., Lozovoi, V.N., Bovkov, I.A., and Kaveshnikov, A.I., Variation in the Mechanical Properties of the Basic Metal in Large-Diameter Pipe with Different Blank-Shaping Methods, Tr. XVIII Mezhdunar. nauchno-teorich. konf. Truby-2011 (Proceedings of Truby-2011 International Pipe Conference), Chelyabinsk: RosNITI, 2011, pp. 44-55.

9. Kuznetsov, E.Ya., Basic Equipment and Technology for External and Internal Coating Application in SELMITRS and BAUHUIS Systems, Tr. XVIII Mezhdunar. nauchno-teorich. konf. Truby-2011 (Proceedings of Truby-2011 International Pipe Conference), Chelyabinsk: RosNITI, 2011, pp. 71-76.

10. Morrison, W.B. and Miller, R.L., Plasticity of Alloys with Supersmall Grains, Sverkhmelkoe zerno v metallakh (Supersmall Grains in Metals), Moscow: Metallurgy, 1983, pp. 181-205.

11. Botvina, L.R., Razrushenie: kinetika, mekhanizmy, obshchie zakonomernosti (Failure: Kinetics, Mechanisms, General Principles), Moscow: Nauka, 2008.

12. Makhutov, N.A., Permyakov, V.N., Botvina, L.R., and Kravtsova, Yu.A., Probl. Bezopasn. Chrezvych. Sit., 2006, no. 3, pp. 65-76.

13. Pyshmintsev, I.Yu., Arabei, A.B., Farber, V.M., et al., Fiz. Met. Metallov., 2012, vol. 113, no. 4, pp. 411-417. 